University of South Carolina

Scholar Commons

7-26-2005

\title{
Cardiorespiratory Fitness Is Inversely Associated With the Incidence of Metabolic Syndrome: A Prospective Study of Men and Women
}

Michael J. LaMonte

Carolyn E. Barlow

Radim Jurca

James B. Kampert

Timothy S. Church

See next page for additional authors

Follow this and additional works at: https://scholarcommons.sc.edu/

sph_epidemiology_biostatistics_facpub

Part of the Public Health Commons

\section{Publication Info}

Published in Circulation, Volume 112, Issue 4, 2005, pages 505-512.

LaMonte, M. J., Barlow, C. E., Jurca, R., Kampert, J. B., Church, T. S., \& Blair, S. N. (2005). Cardiorespiratory fitness is inversely associated with the incidence of metabolic syndrome: A prospective study of men and women. Circulation, 112(4), 505-512.

DOI: 10.1161/CIRCULATIONAHA.104.503805

(c) Circulation, 2005, American Heart Association

http://circ.ahajournals.org/

This Article is brought to you by the Epidemiology and Biostatistics at Scholar Commons. It has been accepted for inclusion in Faculty Publications by an authorized administrator of Scholar Commons. For more information, please contact digres@mailbox.sc.edu. 


\section{Author(s)}

Michael J. LaMonte, Carolyn E. Barlow, Radim Jurca, James B. Kampert, Timothy S. Church, and Steven N. Blair 


\title{
Cardiorespiratory Fitness Is Inversely Associated With the Incidence of Metabolic Syndrome A Prospective Study of Men and Women
}

\author{
Michael J. LaMonte, PhD, MPH; Carolyn E. Barlow, MS; Radim Jurca, PhD; James B. Kampert, PhD; \\ Timothy S. Church, MD, MPH, PhD; Steven N. Blair, PED
}

Background-Few studies have reported the relationship between cardiorespiratory fitness and metabolic syndrome incidence, particularly in women.

Methods and Results -We prospectively studied 9007 men (mean \pm SD age, $44 \pm 9$ years; body mass index, $25 \pm 3 \mathrm{~kg} / \mathrm{m}^{2}$ ) and 1491 women (age, $44 \pm 9$ years; body mass index, $22 \pm 2 \mathrm{~kg} / \mathrm{m}^{2}$ ) who were free of metabolic syndrome and for whom measures of waist girth, resting blood pressure, fasting lipids, and glucose were taken during baseline and follow-up examinations. Baseline cardiorespiratory fitness was quantified as duration of a maximal treadmill test. Metabolic syndrome was defined with NCEP ATP-III criteria. During a mean follow-up of 5.7 years, 1346 men and 56 women developed metabolic syndrome. Age-adjusted incidence rates were significantly lower (linear trend, $P<0.001$ ) across incremental thirds of fitness in men and women. After further adjustment for potential confounders, multivariable hazard ratios for incident metabolic syndrome among men in the low, middle, and upper thirds of fitness, were 1.0 (referent), 0.74 (95\% CI, 0.65 to 0.84 ), and 0.47 (95\% CI, 0.40 to 0.54) (linear trend $P<0.001$ ); in women, they were 1.0 (referent), 0.80 (95\% CI, 0.44 to 1.46 ), and 0.37 (95\% CI, 0.18 to 0.80 ) (linear trend $P=0.01$ ), respectively. Similar patterns of significant inverse associations between fitness and metabolic syndrome incidence were seen when men were stratified on categories of body mass index, age, and number of baseline metabolic risk factors, but patterns were variable in women.

Conclusions-Low cardiorespiratory fitness is a strong and independent predictor of incident metabolic syndrome in women and men. Clinicians should consider the potential benefits of greater cardiorespiratory fitness in the primary prevention of metabolic syndrome, particularly among patients who have already begun to cluster metabolic syndrome components. (Circulation. 2005;112:505-512.)

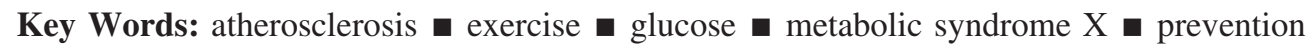

$\mathrm{M}$ etabolic syndrome is a condition of high-risk phenotypes that include elevated blood pressure, dyslipidemia, impaired glycemic control, and abdominal obesity. ${ }^{1}$ The etiology of metabolic syndrome is complex and characterizes defects in several homeostatic regulatory systems ${ }^{2}$ that, when coexisting, increase the risk of cardiovascular events $^{3-5}$ and diabetes. ${ }^{4,6,7}$ Recent data suggest that metabolic syndrome may be particularly associated with significant underlying atherosclerotic coronary disease in women. ${ }^{8}$ Therefore, detecting metabolic syndrome in otherwise asymptomatic individuals has been recognized as a clinical tool for identifying high-risk individuals for intensive primary preventive therapy. ${ }^{9}$

\section{See $\mathrm{p} 453$}

Several investigators have identified predictors of metabolic syndrome. ${ }^{10-16}$ Few studies, however, have included measures of physical activity or cardiorespiratory fitness. ${ }^{10,11,16}$
Experimental data have shown that increases in physical activity improve each metabolic syndrome risk factor. ${ }^{17-21}$ Cross-sectional studies, ${ }^{22,23}$ including our analyses in the Aerobics Center Longitudinal Study (ACLS), ${ }^{24,25}$ have demonstrated an inverse association for physical activity and cardiorespiratory fitness with metabolic syndrome prevalence. Furthermore, a recent study showed that participation in 20 weeks of supervised aerobic exercise training resulted in a $31 \%$ reduction in metabolic syndrome prevalence among 105 adults. $^{21}$

Prospective data on physical activity and cardiorespiratory fitness as predictors of metabolic syndrome incidence are sparse. ${ }^{10,11,16}$ Studies using fitness exposures have consistently shown an inverse association with incident metabolic syndrome, ${ }^{10,11}$ whereas studies using self-reported physical activity exposures have been equivocal. ${ }^{11,16}$ Cardiorespiratory fitness, assessed with maximal exercise testing, is stronger than self-reported physical activity as a predictor of health

Received August 31, 2004; revision received March 10, 2005; accepted March 30, 2005.

From the Cooper Institute, Dallas, Tex.

Correspondence to Dr Michael J. LaMonte, Cooper Institute, 12330 Preston Rd, Dallas, TX 75230. E-mail mlamonte@cooperinst.org

(C) 2005 American Heart Association, Inc. 
outcomes because fitness assessment is less prone to misclassification $^{26}$ and because factors other than physical activity may influence fitness levels and health status through related biological pathways. ${ }^{27} \mathrm{~A}$ weakness in existing prospective data relating activity or fitness with incident metabolic syndrome is a limited understanding of whether the association varies by sex, age, weight status, and the number of baseline metabolic syndrome components. We therefore examined these issues in a large prospective study of men and women.

\section{Methods}

Participants were men and women 20 to 80 years of age who had preventive medical examinations at the Cooper Clinic (Dallas, Tex) between 1979 and 2003 and who are enrolled in the ACLS. 28,29 Inclusion criteria required participants to have at least 2 clinic examinations with complete measurements for each metabolic syndrome variable and a baseline cardiorespiratory fitness measurement $(n=13628)$. Exclusions $(n=3130)$ were prevalent metabolic syndrome $(n=2067)$, an abnormal resting $(n=327)$ or exercise $(n=441)$ ECG, and a history of physician-diagnosed coronary heart disease $(n=48)$, stroke $(n=11)$, or cancer $(n=236)$ at baseline. The remaining 9007 men and 1491 women met all criteria and were included in the analysis. Participants were mostly non-Hispanic whites $(>95 \%)$ of middle to high socioeconomic status. The average number of clinic visits and years between first and last visits were $4.3 \pm 3.3$ (range, 2 to 28 ) and 5.8 \pm 5.1 years (range, 0.01 to 23.9) in men and $3.1 \pm 1.9$ (range, 2 to 16 ) and $5.5 \pm 5.1$ years (range, 0.03 to 22.8 ) in women, respectively. The Cooper Institute Institutional Review Board approved the study protocol, and participants provided written informed consent.

The clinic examination followed a 12-hour fast as described elsewhere. ${ }^{24,28,29}$ Body mass index (BMI; $\mathrm{kg} / \mathrm{m}^{2}$ ) was computed from measured height and weight. Waist girth was measured at the umbilicus. After a brief period of quiet sitting, resting systolic and diastolic blood pressures were recorded as the first and fifth Korotkoff sounds using standard auscultation methods. ${ }^{30}$ Concentrations of triglycerides, HDL cholesterol, and glucose were measured in antecubital venous blood with automated bioassays according to Centers for Disease Control and Prevention standards. ${ }^{28}$

We quantified cardiorespiratory fitness as the duration of a maximal treadmill exercise test using a modified Balke protocol. ${ }^{24,28}$ Patients began walking at $3.3 \mathrm{mph}(88 \mathrm{~m} / \mathrm{min})$ with no elevation. The incline was increased to $2 \%$ after the first minute and was increased $1 \%$ each minute thereafter until the 25 th minute. For participants who were still able to exercise beyond 25 minutes, the elevation was maintained at $25 \%$, and the speed was increased by $0.2 \mathrm{mph}(5.4$ $\mathrm{m} / \mathrm{min}$ ) each minute until volitional exhaustion. Duration of this treadmill test is highly correlated with measured maximal oxygen uptake in men $(r=0.92)$ and women $(r=0.94){ }^{31,32}$ Maximal MET levels of cardiorespiratory fitness $\left(1 \mathrm{MET}=3.5 \mathrm{~mL} \mathrm{O} \cdot \mathrm{kg}^{-1} \cdot \mathrm{min}^{-1}\right)$ were estimated from the final treadmill speed and grade. ${ }^{33}$ Sexspecific distributions of treadmill exercise duration were formed within the following age groups: 20 to 39,40 to 49,50 to 59 , and $\geq 60$ years. Each sex- and age-specific distribution was divided into thirds of low, middle, and high cardiorespiratory fitness (Table 1). Use of tertile cutpoints is not the standard method of categorizing fitness in the ACLS. Previous ACLS reports that showed that low fitness is an independent predictor of mortality have used the lowest fifth of age- and sex-standardized treadmill duration to define low fitness, and moderate fitness and high fitness have been defined by the middle $40 \%$ and upper $40 \%$ of the distribution, respectively. ${ }^{28,29,34}$ In the present analysis, however, low-fit individuals by the previous definition were rarely free of metabolic syndrome at baseline. Therefore, fitness was defined according to tertile cutpoints.

The outcome variable was metabolic syndrome defined as $\geq 3$ of the following criteria ${ }^{1}$ : abdominal obesity (waist girth $>102 \mathrm{~cm} \mathrm{[40}$ in] in men and $>88 \mathrm{~cm}$ [35 in] in women), triglycerides
TABLE 1. Age- and Sex-Specific MET Values According to Tertile of Cardiorespiratory Fitness

\begin{tabular}{lcccccccc}
\hline & \multicolumn{4}{c}{ Men } & & \multicolumn{4}{c}{ Women } \\
\cline { 2 - 4 } \cline { 6 - 7 } Age Groups, y & Low & Middle & High & & Low & Middle & High \\
\hline $20-39$ & $<12.2$ & $12.2-13.9$ & $>13.9$ & & $<9.9$ & $9.9-11.6$ & $>11.6$ \\
$40-49$ & $<11.6$ & $11.6-13.5$ & $>13.5$ & & $<9.3$ & $9.3-11.2$ & $>11.2$ \\
$50-59$ & $<10.8$ & $10.8-12.6$ & $>12.6$ & $<8.5$ & $8.5-9.8$ & $>9.8$ \\
$\geq 60$ & $<9.9$ & $9.9-11.7$ & $>11.7$ & $<8.0$ & $8.0-9.0$ & $>9.0$ \\
\hline
\end{tabular}

$1 \mathrm{MET}=3.5 \mathrm{~mL} \mathrm{O}_{2}$ uptake $\cdot \mathrm{kg}^{-1} \cdot \mathrm{min}^{-1}$. METs were estimated from the final treadmill speed and grade of a modified Balke-Ware protocol as described in Methods.

$\geq 1.69 \mathrm{mmol} / \mathrm{L}(150 \mathrm{mg} / \mathrm{dL}), \mathrm{HDL}<1.04 \mathrm{mmol} / \mathrm{L}(40 \mathrm{mg} / \mathrm{dL})$ in men and $<1.3 \mathrm{mmol} / \mathrm{L}(50 \mathrm{mg} / \mathrm{dL})$ in women, blood pressure $\geq 130 \mathrm{~mm} \mathrm{Hg}$ systolic or $\geq 85 \mathrm{~mm} \mathrm{Hg}$ diastolic, and glucose $\geq 6.1 \mathrm{mmol} / \mathrm{L}$ (110 mg/dL). Histories of physician-diagnosed hypertension and diabetes were included in the definition of abnormal blood pressure and glucose, respectively, as done in other epidemiological studies of metabolic syndrome incidence. ${ }^{3,10,16}$ Other variables included in the analysis were current smoking status, alcohol intake, and family history of hypertension, diabetes, and premature coronary disease obtained from a standardized medical history questionnaire. Alcohol intake was quantified as drinks per week, with a drink standardized to 12 ounces of beer, 5 ounces of wine, or 1.5 ounces of liquor.

\section{Statistical Analysis}

Cases were defined as meeting the metabolic syndrome definition at any clinic examination after baseline. Among noncases, follow-up time was computed as the difference between the date of the baseline and the last clinic examination. Because the exact date of metabolic syndrome development is unknown, we used the midpoint between the date of the case-finding clinic examination and the date of the previous examination when participants were known to be free of metabolic syndrome. Follow-up time among cases was then computed as the difference between this date and the date of the baseline examination. Person-years of exposure were computed as the sum of follow-up time among cases and noncases. Incident rates (per 1000 person-years) were computed as the number of cases divided by person-years of exposure for the total sample according to sex, cardiorespiratory fitness level, and other categories of risk predictors.

We used Cox regression to estimate sex-specific hazard ratios (HRs) and 95\% CIs as an index of the strength of association between cardiorespiratory fitness and incident metabolic syndrome. Multivariable analyses were adjusted for year of baseline examination, age (years), current smoking (yes/no), alcohol intake (drinks/ week), number of baseline metabolic syndrome risk factors $(0,1$, or 2), and family history (yes/no) of hypertension, diabetes, and premature coronary disease. Henceforth, "covariables" refers to these factors unless otherwise specified. Additional Cox regression analyses were performed separately for men and women according to baseline BMI ( $<25$ and $\geq 25 \mathrm{~kg} / \mathrm{m}^{2}$ ), age (20 to 39,40 to 49 , and $\geq 50$ years), and metabolic syndrome components $(0,1$, or 2$)$.

We estimated population-attributable risk (PAR) of metabolic syndrome for the lowest third of cardiorespiratory fitness and each metabolic syndrome risk factor to quantify the influence that eliminating these risk factors might have on metabolic syndrome incidence in the source population of our cohort. PAR was computed as $P_{c}\left(1-1 / \mathrm{HR}_{\text {adj }}\right)$, where $\mathrm{P}_{c}$ is the prevalence of a risk factor among metabolic syndrome cases and $\mathrm{HR}_{\text {adj }}$ is the multivariable adjusted $\mathrm{HR}$ for metabolic syndrome associated with the specified risk factor. ${ }^{35}$ We computed 95\% CIs around the point estimate PAR using standard methods. ${ }^{35}$ There were no a priori hypotheses on sex differences in metabolic syndrome incidence or the association between fitness and metabolic syndrome. Probability values are 2 sided, and $P<0.05$ was regarded as statistically significant. 
TABLE 2. Baseline Characteristics for Men and Women According to Metabolic Syndrome Status at Follow-Up

\begin{tabular}{|c|c|c|c|c|}
\hline & \multicolumn{2}{|c|}{ Men } & \multicolumn{2}{|c|}{ Women } \\
\hline & $\begin{array}{l}\text { Metabolic } \\
\text { Syndrome }\end{array}$ & $\begin{array}{l}\text { No Metabolic } \\
\text { Syndrome }\end{array}$ & $\begin{array}{l}\text { Metabolic } \\
\text { Syndrome }\end{array}$ & $\begin{array}{c}\text { No Metabolic } \\
\text { Syndrome }\end{array}$ \\
\hline $\mathrm{n}$ & 1346 & 7661 & 56 & 1435 \\
\hline Age, y & $44.4 \pm 8.4$ & $43.5 \pm 9.2$ & $48.0 \pm 9.6$ & $44.1 \pm 9.1$ \\
\hline BMl, $\mathrm{kg} / \mathrm{m}^{2}$ & $26.7 \pm 2.9$ & $25.0 \pm 2.6$ & $25.2 \pm 4.0$ & $22.0 \pm 2.8$ \\
\hline Waist, cm & $95.3 \pm 8.1$ & $89.8 \pm 8.0$ & $78.6 \pm 9.0$ & $70.4 \pm 7.9$ \\
\hline Systolic BP, mm Hg & $120.3 \pm 12.0$ & $117.6 \pm 12.0$ & $118.7 \pm 12.8$ & $110.6 \pm 13.0$ \\
\hline Diastolic BP, mm Hg & $80.9 \pm 8.4$ & $78.7 \pm 8.7$ & $79.7 \pm 9.0$ & $74.9 \pm 9.0$ \\
\hline Triglycerides, mmol/L & $1.67 \pm 1.02$ & $1.17 \pm 0.67$ & $1.48 \pm 0.59$ & $0.92 \pm 0.51$ \\
\hline $\mathrm{HDL}-\mathrm{C}, \mathrm{mmol} / \mathrm{L}$ & $1.08 \pm 0.24$ & $1.27 \pm 0.29$ & $1.37 \pm 0.25$ & $1.61 \pm 0.34$ \\
\hline Glucose, $\mathrm{mmol} / \mathrm{L}$ & $5.50 \pm 0.57$ & $5.40 \pm 0.62$ & $5.28 \pm 0.49$ & $5.18 \pm 0.81$ \\
\hline Maximal METs & $11.8 \pm 1.9$ & $12.7 \pm 2.3$ & $9.0 \pm 1.9$ & $10.1 \pm 2.0$ \\
\hline Current smoker, \% & 16.5 & 14.1 & 10.7 & 8.0 \\
\hline$\geq 5$ Alcoholic drinks per week, $\%$ & 43.2 & 43.1 & 19.6 & 24.1 \\
\hline \multicolumn{5}{|l|}{ Family history, \% } \\
\hline Hypertension & 44.7 & 41.9 & 48.2 & 53.2 \\
\hline Diabetes & 29.3 & 25.8 & 41.1 & 33.9 \\
\hline Premature coronary heart disease & 17.9 & 15.5 & 23.2 & 16.8 \\
\hline Abdominal obesity, $\%$ & 15.9 & 5.3 & 10.7 & 2.8 \\
\hline High blood pressure, $\%$ & 38.0 & 29.9 & 39.2 & 19.1 \\
\hline High triglycerides, \% & 32.9 & 12.5 & 25.0 & 6.0 \\
\hline High glucose, \% & 8.6 & 7.2 & 8.9 & 3.9 \\
\hline Low HDL-C, \% & 41.0 & 20.3 & 35.7 & 14.0 \\
\hline \multicolumn{5}{|l|}{ No. of metabolic syndrome factors, $\%$} \\
\hline 0 & 14.3 & 43.5 & 23.2 & 61.4 \\
\hline 1 & 34.8 & 37.6 & 33.9 & 31.2 \\
\hline 2 & 50.9 & 18.9 & 42.9 & 7.4 \\
\hline
\end{tabular}

\section{Results}

A total of 1346 men and 56 women developed metabolic syndrome during 52060 and 8275 person-years of exposure, respectively. The crude incidence rate of metabolic syndrome per 1000 person-years was 25.9 in men and 6.8 in women. Men and women who developed metabolic syndrome were broadly similar in age, average risk factor values, and average maximal MET levels of cardiorespiratory fitness as their same-sex peers who remained free of metabolic syndrome (Table 2). In men and women, cases had higher prevalence of each metabolic syndrome risk factor at baseline than noncases. The number of baseline metabolic risk factors was significantly associated with metabolic syndrome case status in men $\left(\chi_{\mathrm{df}=1}^{2}=709.4 ; P\right.$ for trend $\left.<0.001\right)$ and in women $\left(\chi_{\mathrm{df}=1}^{2}=68.9 ; P\right.$ for trend $\left.<0.001\right)$. These values were similar for cases and noncases in both sexes.

We observed a steep inverse gradient (linear trend, $P<0.001)$ of age-adjusted metabolic syndrome incidence rates across incremental thirds of cardiorespiratory fitness in men and women (the Figure). Multivariable Cox regression was then used to quantify the strength of association between fitness and incidence of metabolic syndrome with adjustment for covariables (Table 3). The adjusted risk of metabolic syndrome was $26 \%$ (16\% to $35 \%$ ) and $53 \%$ (46\% to $60 \%$ ) lower for men in the middle and upper thirds of fitness (linear trend $P<0.001$ ), respectively, compared with men in the lower third. In women, the adjusted risk of metabolic syndrome was $20 \%$ ( $-46 \%$ to $56 \%$ ) and $63 \%$ (20\% to $82 \%$ ) lower among those in the middle and upper thirds of fitness (linear trend $P=0.01$ ), respectively, compared with women in the lower third. On average, a 1-MET increment in maximal treadmill performance was associated with a $16 \%(12 \%$ to $17 \%, P<0.001)$ and $17 \%$ (4\% to $29 \%, P=0.02)$ lower multivariable-adjusted risk of metabolic syndrome in men and women, respectively.

We examined whether the association between cardiorespiratory fitness and incident metabolic syndrome varied according to strata of BMI, age, and number of metabolic syndrome components at baseline (Table 3). An inverse dose-response relationship $(P<0.001)$ between fitness and metabolic syndrome was observed in men who were normal weight (BMI $<25 \mathrm{~kg} / \mathrm{m}^{2}$ ) and overweight/obese (BMI $\geq 25$ $\left.\mathrm{kg} / \mathrm{m}^{2}\right)$. Men in the top two thirds of the fitness distribution in 


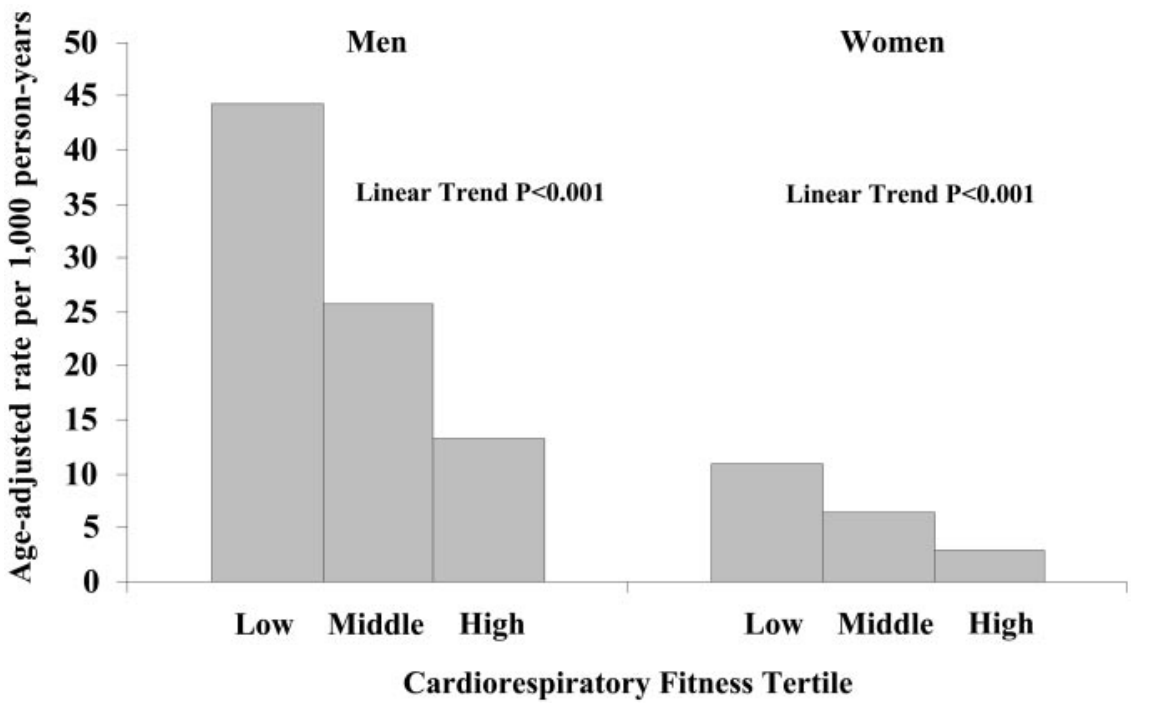

Age-adjusted incidence rates (per 1000 person-years) of metabolic syndrome by thirds of cardiorespiratory fitness in men and women. Number at risk (and number of cases) in low, middle, and high tertile of fitness was 3011 (636), 2984 (437), and 3012 (273) in men and 494 (28), 500 (19), and 497 (9) in women, respectively.

the normal and overweight/obese categories, respectively, had an $\approx 21 \%$ and $\approx 42 \%$ lower risk of developing metabolic syndrome than men in the lowest third of fitness within the same weight category $(P<0.001)$. A trend for lower metabolic syndrome risk across thirds of fitness was present but not significant for women in the normal weight category.

Strong inverse gradients in the risk of metabolic syndrome were seen across thirds of fitness in men who were 20 to 39, 40 to 49 , and $\geq 50$ years. The adjusted risks of metabolic syndrome were $22 \%$ to $32 \%$ and $52 \%$ to $54 \%$ lower for men in the middle and upper thirds of fitness, respectively, compared with men of the same age who were in the lowest third $(P<0.001)$. A nonsignificant trend for lower metabolic syndrome risk with higher fitness was observed for women in each age group.

We examined the influence that the number of baseline metabolic syndrome risk factors had on the association between fitness and metabolic syndrome. The number of metabolic syndrome components was a significant predictor of developing metabolic syndrome in men and women. After adjustment for age and year of baseline examination, HRs for metabolic syndrome in individuals with 1 and 2 baseline risk factors were $2.9(95 \% \mathrm{CI}, 2.4$ to $3.4 ; P<0.001)$ and $9.0(95 \%$ CI, 7.6 to 10.6; $P<0.001)$ in men and 2.9 (95\% CI, 1.4 to 5.9; $P=0.004)$ and $16.3(95 \% \mathrm{CI}, 8.1$ to $32.8 ; P<0.001)$ in women, respectively, compared with their same-sex peers with no metabolic syndrome components at baseline. Significant $(P<0.001)$ inverse associations between fitness and metabolic syndrome were seen in men with 0,1 , and 2 metabolic syndrome risk factors at baseline (Table 3). Adjusted HRs were $22 \%$ to $35 \%$ and $43 \%$ to $63 \%$ lower for men in the middle and upper thirds of fitness, respectively, compared with men in the lowest third $(P<0.001)$. Similar patterns of association were seen in women, but a significant trend was seen only for those with no baseline metabolic syndrome components $(P=0.02)$.

The relative importance of low cardiorespiratory fitness and metabolic risk factors as predictors of metabolic syndrome is shown in Table 4. After adjustment for age, smoking, year of baseline examination, and each risk factor in
Table 4, low fitness was a significant predictor of metabolic syndrome in men but not women. We computed PAR estimates to place the risk of metabolic syndrome for each exposure in the context of population-disease burden. Accordingly, if all individuals from our population sample who were in the lowest third of fitness had been in the middle or highest third of fitness, the incidence of metabolic syndrome may have been $15 \%$ and $20 \%$ lower in men and women, respectively. Because the metabolic risk factor may be viewed as intermediate in the causal pathway from fitness to metabolic syndrome, we also computed HRs and PAR estimates for low fitness, adjusting only for age, smoking, and examination year. The HRs and PARs for metabolic syndrome associated with low fitness were 2.3 (95\% CI, 2.1 to 2.6) and $26.7 \%$ (95\% CI, 22.9 to 30.4) for men and $2.4(95 \%$ CI, 1.4 to 4.0 ) and $28.9 \%$ (95\% CI, 7.5 to 45.3 ) for women.

\section{Discussion}

Metabolic syndrome afflicts $\approx 25 \%$ of US adults and is associated with increased risk of cardiovascular disease and diabetes. ${ }^{1}$ Current clinical guidelines indicate a role for physical activity in the etiology and management of metabolic syndrome. ${ }^{9}$ Whether higher levels of activity and fitness may help prevent metabolic syndrome development is less understood, particularly in women. ${ }^{10,11,16}$ The results reported here show that cardiorespiratory fitness, an objective marker of recent physical activity patterns, was inversely associated with metabolic syndrome incidence in asymptomatic adults. The overall findings are consistent in women and men and hold after adjustment for several potential confounders, including the number of metabolic syndrome components at baseline. Strengths of the study are the use of maximal treadmill exercise testing to quantify cardiorespiratory fitness; use of a comprehensive physical examination, health history, and resting and stress ECGs to rule out subclinical disease at baseline; use of a large sample of men and women to permit meaningful sex-specific analyses; and an extensive follow-up for incident cases.

Associations between physical activity and metabolic syndrome incidence have been inconsistent, ${ }^{11,16}$ which may 
TABLE 3. HRs and $95 \%$ Cls for Metabolic Syndrome According to Cardiorespiratory Fitness and Other Predictors

\begin{tabular}{|c|c|c|c|c|c|c|c|c|}
\hline & \multirow[b]{2}{*}{$\mathrm{N}$} & \multirow[b]{2}{*}{ Cases } & \multirow{2}{*}{$\begin{array}{c}\text { Follow-Up, } \\
\text { person-y }\end{array}$} & \multirow{2}{*}{$\begin{array}{l}\text { Age-Adjusted } \\
\text { Rate per } \\
1000 \text { person-y }\end{array}$} & \multicolumn{3}{|c|}{ Cardiorespiratory Fitness Tertile } & \multirow{2}{*}{$\begin{array}{c}\text { Linear Trenc } \\
P\end{array}$} \\
\hline & & & & & Low & Middle & High & \\
\hline \multicolumn{9}{|l|}{ Men } \\
\hline Total & 9007 & 1346 & 52241 & $25.8^{*}$ & 1.0 (Referent) & $0.74(0.65-0.84)$ & $0.47(0.40-0.54)$ & $<0.001$ \\
\hline \multicolumn{9}{|c|}{ BMI, $\mathrm{kg} / \mathrm{m}^{2}$} \\
\hline$<25$ & 4440 & 377 & 29866 & 13.0 & 1.0 (Referent) & $0.77(0.59-0.99)$ & $0.57(0.44-0.74)$ & $<0.001$ \\
\hline$\geq 25$ & 4567 & 969 & 22228 & 43.0 & 1.0 (Referent) & $0.81(0.70-0.93)$ & $0.59(0.48-0.71)$ & $<0.001$ \\
\hline \multicolumn{9}{|l|}{ Age, y } \\
\hline $20-39$ & 3121 & 388 & 16218 & $23.3^{*}$ & 1.0 (Referent) & $0.78(0.62-0.98)$ & $0.48(0.36-0.64)$ & $<0.001$ \\
\hline $40-49$ & 3587 & 600 & 18311 & 32.9 & 1.0 (Referent) & $0.75(0.62-0.90)$ & $0.46(0.37-0.58)$ & $<0.001$ \\
\hline$\geq 50$ & 2299 & 358 & 11255 & 32.5 & 1.0 (Referent) & $0.68(0.53-0.87)$ & $0.47(0.35-0.62)$ & $<0.001$ \\
\hline \multicolumn{9}{|c|}{ Metabolic syndrome risk factors at baseline } \\
\hline 0 & 3524 & 193 & 23839 & 8.4 & 1.0 (Referent) & $0.65(0.46-0.92)$ & $0.37(0.26-0.53)$ & $<0.001$ \\
\hline 1 & 3353 & 468 & 19410 & 24.4 & 1.0 (Referent) & $0.70(0.57-0.86)$ & $0.43(0.34-0.54)$ & $<0.001$ \\
\hline 2 & 2130 & 685 & 8841 & 76.1 & 1.0 (Referent) & $0.78(0.66-0.93)$ & $0.57(0.45-0.71)$ & $<0.001$ \\
\hline \multicolumn{9}{|l|}{ Women } \\
\hline Total & 1491 & 56 & 8350 & $6.7^{\star}$ & 1.0 (Referent) & $0.80(0.44-1.46)$ & $0.37(0.18-0.80)$ & 0.01 \\
\hline \multicolumn{9}{|c|}{ BMI, $\mathrm{kg} / \mathrm{m}^{2}$} \\
\hline$<25$ & 1278 & 31 & 7523 & 4.2 & 1.0 (Referent) & $0.96(0.42-2.19)$ & $0.48(0.18-1.24)$ & 0.13 \\
\hline$\geq 25$ & 213 & 25 & 749 & 32.8 & 1.0 (Referent) & $1.04(0.41-2.69)$ & $1.33(0.29-6.22)$ & 0.75 \\
\hline \multicolumn{9}{|l|}{ Age, y } \\
\hline 20-39 & 459 & 12 & 2614 & $4.7^{\star}$ & 1.0 (Referent) & $0.99(0.24-4.11)$ & $0.46(0.07-2.79)$ & 0.43 \\
\hline $40-49$ & 614 & 20 & 3122 & 6.4 & 1.0 (Referent) & $1.37(0.51-3.65)$ & $0.24(0.05-1.15)$ & 0.11 \\
\hline$\geq 50$ & 418 & 24 & 1875 & 12.7 & 1.0 (Referent) & $0.47(0.17-1.28)$ & $0.36(0.12-1.07)$ & 0.05 \\
\hline \multicolumn{9}{|c|}{ Metabolic syndrome risk factors at baseline } \\
\hline 0 & 894 & 13 & 5320 & 2.7 & 1.0 (Referent) & $0.35(0.10-1.24)$ & $0.15(0.03-1.24)$ & 0.02 \\
\hline 1 & 467 & 19 & 2441 & 7.8 & 1.0 (Referent) & $1.17(0.42-3.27)$ & $0.58(0.17-2.03)$ & 0.43 \\
\hline 2 & 130 & 24 & 510 & 44.3 & 1.0 (Referent) & $0.64(0.25-1.68)$ & $0.34(0.09-1.27)$ & 0.09 \\
\hline
\end{tabular}

The lowest third of fitness is the referent group. The HRs for the total sample of men and women and within stratum of BMI and age are adjusted for age, current smoking, alcohol intake, family history of disease, year of baseline examination, and number of baseline metabolic risk factors. The HRs within stratum of baseline metabolic syndrome risk factors are adjusted for each of these covariables except number of baseline metabolic syndrome risk factors.

${ }^{*}$ The incidence rates for the total sample of men and women and across stratum of age are crude rates.

largely reflect the inaccuracy of self-reported physical activity assessment, particularly in women. ${ }^{36}$ Cardiorespiratory fitness, an objective measure of recent physical activity patterns, ${ }^{26}$ is less prone to misclassification than self-reported physical activity habits. The 2 existing studies that used maximal cardiorespiratory fitness exposures have shown an inverse association with metabolic syndrome incidence. ${ }^{10,11}$ Laaksonen et al $^{11}$ reported $47 \%$ and $75 \%$ lower odds of developing metabolic syndrome among men in the middle and highest thirds of measured maximal oxygen uptake, respectively, compared with men in the lowest third. The association, however, was no longer significant after adjustment for baseline metabolic risk factors. Carnethon et al ${ }^{10}$ reported on men and women combined and showed that only participants in the highest $40 \%$ of maximal treadmill performance were protected against developing metabolic syndrome. In our analysis, compared with individuals in the lowest third of fitness, the risk of developing metabolic syndrome was $20 \%$ to $26 \%$ lower among participants in the middle third and $53 \%$ to $63 \%$ lower among those in the highest third. The protective effect of fitness was observed in women and men and remained significant even after adjustment for the number of baseline metabolic syndrome factors. Our findings extend existing data by demonstrating that moderate and high levels of fitness provide substantial protection against developing metabolic syndrome in women and in men. Controlled clinical trials are needed to confirm these epidemiological observations.

Metabolic syndrome occurs across the distribution of age and BMI, although the prevalence is higher in older age groups and in overweight and obese individuals. ${ }^{37}$ In our study, the pattern and strength of the inverse association between fitness and metabolic syndrome were similar across a broad range of ages ( 20 to $>50$ years) in our cohort of men. The same overall pattern of association was observed in these age categories for women; however, the small number of cases limited the statistical power to detect significant differences. Our findings underscore the importance of adequate 
TABLE 4. Relative Association of Low Fitness and Each Metabolic Syndrome Risk Factor With Incident Metabolic Syndrome and the Related PAR in Men and Women

\begin{tabular}{lrrrrr}
\hline & $\begin{array}{c}\text { Prevalence, } \\
\%^{*}\end{array}$ & HR $\dagger$ & $95 \% \mathrm{Cl}$ & $\begin{array}{c}\text { PAR, } \\
\% \neq\end{array}$ & $95 \% \mathrm{Cl}$ \\
\hline Men & & & & & \\
$\quad$ Low fitness & 33.4 & 1.45 & $1.30-1.63$ & 14.7 & $10.0-19.1$ \\
Abdominal obesity & 6.9 & 4.51 & $3.84-5.30$ & 12.3 & $10.3-14.4$ \\
High blood pressure & 31.2 & 2.17 & $1.92-2.45$ & 20.5 & $17.0-23.9$ \\
High glucose & 7.4 & 2.01 & $1.65-2.44$ & 4.3 & $2.7-5.9$ \\
High triglycerides & 15.6 & 3.21 & $2.84-3.64$ & 22.6 & $19.7-25.5$ \\
Low HDL & 14.8 & 2.87 & $2.54-3.23$ & 26.7 & $23.3-30.0$ \\
Women & & & & & \\
Low fitness & 33.1 & 1.64 & $0.95-2.81$ & 19.5 & $-5.1-38.4$ \\
Abdominal obesity & 3.2 & 5.26 & $2.06-13.4$ & 8.7 & $0.0-16.6$ \\
High blood pressure & 19.9 & 2.81 & $1.58-5.03$ & 25.3 & $7.4-39.8$ \\
High glucose & 4.1 & 3.80 & $1.45-9.99$ & 6.6 & $-1.4-13.9$ \\
High triglycerides & 6.8 & 4.78 & $2.48-9.21$ & 19.7 & $6.6-31.3$ \\
Low HDL & 14.8 & 4.53 & $2.55-8.07$ & 27.8 & $12.2-40.7$ \\
\hline
\end{tabular}

*Prevalence in the overall sample of men or women.

†Adjusted for age, smoking, year of baseline examination, and each of the other variables in the table.

fPAR computed as $P_{c}\left(1-1 / H R_{a d i}\right)$, where $P_{c}$ is the prevalence of the risk factor among metabolic syndrome cases and $\mathrm{HR}_{\mathrm{adj}}$ is the multivariable $\mathrm{HR}$ for metabolic syndrome associated with the specified risk factor. $P_{\mathrm{c}}$ (ordered as listed in the table) was $47.3,15.9,38.0,8.6,32.9$, and 41.0 in men and 50.0, $10.7,39.3,8.9,25.0$, and 35.7 in women.

cardiorespiratory fitness to avoid the clustering of metabolic risk factors in young and middle-aged adulthood. The distribution of metabolic syndrome cases by fitness tertiles was not adequate for meaningful analyses in the $>60$-year-old age stratum; thus, additional data are needed to verify our findings in older individuals.

In our study, metabolic syndrome developed among individuals who were normal weight as well as in those who were overweight/obese at baseline. Strong inverse gradients in the adjusted HR of metabolic syndrome were seen across fitness levels in normal weight and overweight/obese men. This is contrary to findings by the CARDIA investigators, who reported an inverse association between fitness and metabolic syndrome only in participants with BMI $<30 \mathrm{~kg} / \mathrm{m}^{2},{ }^{10}$ but consistent with data in Finnish men that indicated the association between fitness and metabolic syndrome was independent of BMI. ${ }^{11}$ The association between fitness and metabolic syndrome in both weight categories among our women was nonsignificant perhaps because of low statistical power. Our data and those reported by others ${ }^{11}$ suggest that higher cardiorespiratory fitness contributes to the prevention of metabolic syndrome even in individuals who are overweight or obese. Additional data on this issue are needed in women and in individuals with $\mathrm{BMI}>35 \mathrm{~kg} / \mathrm{m}^{2}$.

It is logical to assume that individuals with 1 or 2 of the metabolic syndrome components at baseline would be more susceptible to expressing metabolic syndrome than individuals with none at baseline. Indeed, we observed that $51 \%$ of men and $43 \%$ of women who developed metabolic syndrome had 2 baseline risk factors compared with $19 \%$ and $7 \%$ of noncases, respectively. The adjusted HRs for metabolic syndrome in men and women with 1 or 2 baseline risk factors were 3- to 16-fold higher compared with participants with no baseline risk factors. Even after adjustment for the number of baseline metabolic risk factors, fitness was a significant predictor of metabolic syndrome in women and men. Inverse associations between fitness and metabolic syndrome were also observed in subgroups of men and women with 0,1 , and 2 baseline risk factors, although the analysis in women was limited by low statistical power. Our data suggest that higher fitness levels confer protection against metabolic syndrome even in individuals with increased susceptibility because of existing metabolic risk factors. Clinicians should consider the potential benefits of greater cardiorespiratory fitness in the primary prevention of metabolic syndrome in patients who have already begun to cluster metabolic syndrome components.

When regressed simultaneously, low cardiorespiratory fitness and each metabolic syndrome risk factor were significantly associated with developing metabolic syndrome in men. Among women, a direct association was observed between low fitness and metabolic syndrome, but the association was not statistically significant after adjustment for each metabolic syndrome risk factor. Most of the predictors in the analysis were themselves components of metabolic syndrome; therefore, it is not surprising that their relative strength of association is somewhat higher than seen for low fitness, although fitness was still a significant predictor in men. Based on PAR estimates, if there were no individuals in the lowest third of fitness, the incidence of metabolic syndrome would be $15 \%$ and $20 \%$ lower in men and women, respectively. Some authors debate whether an exposure (eg, fitness) should be adjusted for risk factors that may be intermediate in the exposure-outcome causal pathway. ${ }^{38,39}$ Therefore, we computed HRs and PARs for metabolic syndrome associated with low fitness adjusted only for age, smoking, and year of baseline examination. As expected, these PAR estimates of $27 \%$ for men and $29 \%$ for women were somewhat higher than the previously discussed PARs computed from the fully adjusted HRs. The comparable PAR estimates for metabolic syndrome associated with low fitness and the metabolic risk factors in our cohort suggest that improving population fitness levels should be given consideration similar to that given to modifying conventional metabolic risk factors for lowering the disease burden of metabolic syndrome.

Although genetics contribute to maximal cardiorespiratory fitness, the principal determinant is physical activity. ${ }^{40} \mathrm{Car}-$ diorespiratory fitness has been closely associated with the reported physical activity habits in the ACLS ${ }^{34,41}$ and other studies of fitness and metabolic syndrome incidence. ${ }^{10,11}$ For most individuals, cardiorespiratory fitness improvements can be obtained through regular participation in moderate and vigorous levels of physical activity. ${ }^{33}$ Regular physical activity is a low-cost, safe therapy with minimal adverse side effects ${ }^{33}$ and favorable benefits on a broad spectrum of health parameters, ${ }^{28,29,34}$ including each metabolic syndrome component. ${ }^{17-21}$ Pharmacological intervention for metabolic syn- 
drome would require multiple agents, which increases costs and risks of adverse effects. Therefore, promoting higher population levels of cardiorespiratory fitness through greater physical activity may be the most prudent clinical and public health strategy for the primary prevention of metabolic syndrome.

Our study has limitations that should be considered. Study findings apply primarily to white men and women with higher socioeconomic affluence. Although the external validity of our data is therefore limited, the homogeneity of our population sample reduces confounding by these sociodemographic factors, which enhances internal validity. Although the overall pattern and strength of association between cardiorespiratory fitness and incident metabolic syndrome were similar in men and women, subgroup analyses in women were underpowered. Additional data are needed to better establish the influence of cardiorespiratory fitness on metabolic syndrome incidence among clinically relevant subgroups of women.

We conclude that cardiorespiratory fitness is inversely associated with metabolic syndrome incidence in women and men and that the association is strong, graded, and biologically plausible. Randomized controlled clinical trials are needed to confirm the epidemiological observations reported here and elsewhere. Still, we believe that clinicians should counsel their sedentary patients to become more physically activity and to improve their cardiorespiratory fitness as part of the primary prevention of metabolic syndrome.

\section{Acknowledgments}

This work was supported by NIH grants AG06945 and HL62508. Additional support has been provided by the Communities Foundation of Texas on recommendation of Nancy Ann and Ray L. Hunt. We thank Dr Kenneth H. Cooper for establishing the Aerobics Center Longitudinal Study, the Cooper Clinic physicians and technicians for collecting the baseline data, and Melba Morrow for editorial assistance.

\section{References}

1. Grundy SM, Brewer HB Jr, Cleeman JI, Smith SC Jr, Lenfant C. Definition of metabolic syndrome: report of the National Heart, Lung, and Blood Institute/American Heart Association conference on scientific issues related to definition. Circulation. 2004;109:433-438.

2. Hopkins PN, Hunt SC, Wu LL, Williams GH, Williams RR. Hypertension, dyslipidemia, and insulin resistance: links in a chain or spokes on a wheel? Curr Opin Lipidol. 1996;7:241-253.

3. Lakka HM, Laaksonen DE, Lakka TA, Niskanen LK, Kumpusalo E, Tuomilehto J, Salonen JT. The metabolic syndrome and total and cardiovascular disease mortality in middle-aged men. JAMA. 2002;288: 2709-2716.

4. Sattar N, Gaw A, Scherbakova O, Ford I, O'Reilly DS, Haffner SM, Isles C, Macfarlane PW, Packard CJ, Cobbe SM, Shepherd J. Metabolic syndrome with and without C-reactive protein as a predictor of coronary heart disease and diabetes in the West of Scotland Coronary Prevention Study. Circulation. 2003;108:414-419.

5. Hu G, Qiao Q, Tuomilehto J, Balkau B, Borch-Johnsen K, Pyorala K. Prevalence of the metabolic syndrome and its relation to all-cause and cardiovascular mortality in nondiabetic European men and women. Arch Intern Med. 2004;164:1066-1076.

6. Lorenzo C, Okoloise M, Williams K, Stern MP, Haffner SM. The metabolic syndrome as predictor of type 2 diabetes: the San Antonio Heart Study. Diabetes Care. 2003;26:3153-3159.

7. Laaksonen DE, Lakka HM, Niskanen LK, Kaplan GA, Salonen JT, Lakka TA. Metabolic syndrome and development of diabetes mellitus: application and validation of recently suggested definitions of the metabolic syndrome in a prospective cohort study. Am J Epidemiol. 2002;156: 1070-1077.

8. Marroquin OC, Kip KE, Kelley DE, Johnson BD, Shaw LJ, Bairey Merz CN, Sharaf BL, Pepine CJ, Sopko G, Reis SE. Metabolic syndrome modifies the cardiovascular risk associated with angiographic coronary artery disease in women: a report from the Women's Ischemia Syndrome Evaluation. Circulation. 2004;109:714-721.

9. Grundy SM, Hansen B, Smith SC Jr, Cleeman JI, Kahn RA. Clinical management of metabolic syndrome: report of the American Heart Association/National Heart, Lung, and Blood Institute/American Diabetes Association conference on scientific issues related to management. Circulation. 2004:109:551-556.

10. Carnethon MR, Gidding SS, Nehgme R, Sidney S, Jacobs DR Jr, Liu K. Cardiorespiratory fitness in young adulthood and the development of cardiovascular disease risk factors. JAMA. 2003;290:3092-3100.

11. Laaksonen DE, Lakka HM, Salonen JT, Niskanen LK, Rauramaa R, Lakka TA. Low levels of leisure-time physical activity and cardiorespiratory fitness predict development of the metabolic syndrome. Diabetes Care. 2002;25:1612-1618.

12. Haffner SM, Valdez RA, Hazuda HP, Mitchell BD, Morales PA, Stern MP. Prospective analysis of the insulin-resistance syndrome (syndrome X). Diabetes. 1992;41:715-722.

13. Liese AD, Mayer-Davis EJ, Tyroler HA, Davis CE, Keil U, Duncan BB, Heiss G. Development of the multiple metabolic syndrome in the ARIC cohort: joint contribution of insulin, BMI, and WHR: Atherosclerosis Risk in Communities. Ann Epidemiol. 1997;7:407-416.

14. Han TS, Sattar N, Williams K, Gonzalez-Villalpando C, Lean ME, Haffner SM. Prospective study of C-reactive protein in relation to the development of diabetes and metabolic syndrome in the Mexico City Diabetes Study. Diabetes Care. 2002;25:2016-2021.

15. Han TS, Williams K, Sattar N, Hunt KJ, Lean ME, Haffner SM. Analysis of obesity and hyperinsulinemia in the development of metabolic syndrome: San Antonio Heart Study. Obes Res. 2002;10:923-931.

16. Palaniappan L, Carnethon MR, Wang Y, Hanley AJ, Fortmann SP, Haffner SM, Wagenknecht L. Predictors of the incident metabolic syndrome in adults: the Insulin Resistance Atherosclerosis Study. Diabetes Care. 2004;27:788-793.

17. Kelley DE, Goodpaster BH. Effects of exercise on glucose homeostasis in Type 2 diabetes mellitus. Med Sci Sports Exerc. 2001;33:S495-S501.

18. Leon AS, Sanchez OA. Response of blood lipids to exercise training alone or combined with dietary intervention. Med Sci Sports Exerc. 2001;33:S502-S515.

19. Fagard RH. Exercise characteristics and the blood pressure response to dynamic physical training. Med Sci Sports Exerc. 2001;33:S484-S492.

20. Ross R, Janssen I. Physical activity, total and regional obesity: doseresponse considerations. Med Sci Sports Exerc. 2001;33:S521-S527.

21. Katzmarzyk PT, Leon AS, Wilmore JH, Skinner JS, Rao DC, Rankinen $\mathrm{T}$, Bouchard C. Targeting the metabolic syndrome with exercise: evidence from the HERITAGE Family Study. Med Sci Sports Exerc. 2003;35:1703-1709.

22. Irwin ML, Ainsworth BE, Mayer-Davis EJ, Addy CL, Pate RR, Durstine JL. Physical activity and the metabolic syndrome in a tri-ethnic sample of women. Obes Res. 2002;10:1030-1037.

23. Lakka TA, Laaksonen DE, Lakka HM, Mannikko N, Niskanen LK, Rauramaa R, Salonen JT. Sedentary lifestyle, poor cardiorespiratory fitness, and the metabolic syndrome. Med Sci Sports Exerc. 2003;35: $1279-1286$.

24. Jurca R, LaMonte MJ, Church TS, Earnest CP, FitzGerald SJ, Barlow CE, Jordan AN, Kampert JB, Blair SN. Associations of muscle strength and aerobic fitness with metabolic syndrome in men. Med Sci Sports Exerc. 2004;36:1301-1307.

25. Farrell SW, Cheng YJ, Blair SN. Prevalence of the metabolic syndrome across cardiorespiratory fitness levels in women. Obes Res. 2004;12: $824-830$.

26. Blair SN, Cheng Y, Holder JS. Is physical activity or physical fitness more important in defining health benefits? Med Sci Sports Exerc. 2001; 33:S379-S399.

27. Haskell WL Physical activity and health: need to define the required stimulus. Am J Cardiol. 1985;55:4D-9D.

28. Blair SN, Kohl HW III, Paffenbarger RS Jr, Clark DG, Cooper KH, Gibbons LW. Physical fitness and all-cause mortality: a prospective study of healthy men and women. JAMA. 1989;262:2395-2401.

29. Blair SN, Kampert JB, Kohl HW, Barlow CE, Macera CA, Paffenbarger RSJ, Gibbons LW. Influences of cardiorespiratory fitness and other pre- 
cursors on cardiovascular disease and all-cause mortality in men and women. JAMA. 1996;276:205-210.

30. Perloff D, Grim C, Flack J, Frohlich ED, Hill M, McDonald M, Morgenstern BZ. Human blood pressure determination by sphygmomanometry. Circulation. 1993;88:2460-2470.

31. Pollock ML, Bohannon RL, Cooper KH, Ayres JJ, Ward A, White SR Linnerud AC. A comparative analysis of four protocols for maximal treadmill stress testing. Am Heart J. 1976;92:39-46.

32. Pollock ML, Foster C, Schmidt D, Hellman C, Linnerud AC, Ward A. Comparative analysis of physiologic responses to three different maximal graded exercise test protocols in healthy women. Am Heart J. 1982;103: 363-373.

33. American College of Sports Medicine. ACSM's Guidelines for Exercise Testing and Prescription. 6th ed. Philadelphia, Pa: Lippincott Williams \& Wilkins; 2000.

34. Kampert JB, Blair SN, Barlow CE, Kohl HW III. Physical activity, physical fitness, and all-cause and cancer mortality: a prospective study of men and women. Ann Epidemiol. 1996;6:452-457.

35. Rothman KJ, Greenland S. Modern Epidemiology. 2nd ed. Philadelphia, Pa: Lippincott-Raven Publishers; 1998.
36. LaMonte MJ, Ainsworth BE. Quantifying energy expenditure and physical activity in the context of dose response. Med Sci Sports Exerc. 2001;33:S370-S378.

37. Park YW, Zhu S, Palaniappan L, Heshka S, Carnethon MR, Heymsfield SB. The metabolic syndrome: prevalence and associated risk factor findings in the US population from the Third National Health and Nutrition Examination Survey, 1988-1994. Arch Intern Med. 2003;163: 427-436.

38. Kraemer HC, Stice E, Kazdin A, Offord D, Kupfer D. How do risk factors work together? Mediators, moderators, and independent, overlapping, and proxy risk factors. Am J Psychiatry. 2001;158:848-856.

39. Manson JE, Stampfer MJ, Hennekens CH, Willett WC. Body weight and longevity: a reassessment. JAMA. 1987;257:353-358.

40. Bouchard C, Pérusse L. Heredity, activity level, fitness, and health. In: Bouchard C, Shephard RJ, Stephens T, eds. Physical Activity, Fitness, and Health: International Proceedings and Consensus Statement. Champaign, Ill: Human Kinetics Publishers; 1994:106-118.

41. Jackson AS, Kampert JB, Barlow CE, Morrow JR Jr, Church TS, Blair SN. Longitudinal changes in cardiorespiratory fitness: measurement error or true change? Med Sci Sports Exerc. 2004;36:1175-1180. 